\title{
VISÃO DA EQUIPE ESCOLAR SOBRE PARTICIPAÇÃO: CONCEITO, DESAFIOS E POSSIBILIDADES
}

Mariana Aparecida de Almeida Laurentino, Vanda Moreira Machado Lima.

Universidade Estadual Paulista - UNESP, Curso de Pedagogia Departamento de Educação, Presidente Prudente, SP. Email: Mariana1995laurentino@gmail.com. Agência de fomento: FAPESP no: 201600450-4

\section{RESUMO}

Este artigo é um recorte da pesquisa de iniciação científica (FAPESP) realizada em duas escolas públicas municipais, que visa investigar a participação dos alunos na gestão da escola pública, ciclo I do ensino fundamental. Contudo, o objetivo deste artigo é identificar e refletir a visão da equipe escolar sobre participação, enfatizando conceito, desafios e possibilidades. A pesquisa se insere na abordagem qualitativa e, utilizou como instrumentos na produção de dados: pesquisa bibliográfica, depoimentos e a análise de conteúdo. Os dados empíricos evidenciaram que os sujeitos acreditam que a participação está mais relacionada com o estar presente. Os desafios centram-se nos conteúdos curriculares, na quantidade de disciplinas, ansiedade de se escolarizar as crianças, bem como, no excessivo tempo que passam na escola. Quanto às possibilidades, enfatizamos: o trabalho com representantes de alunos, projetos, votação e liberdade para decisão e escolha, criação de regras e o trabalho com atividades extracurriculares e atividades de civilidade.

Palavras-Chave: Participação. Equipe Escolar. Democracia. Alunos.

\section{VISION OF THE SCHOOL TEAM ON PARTICIPATION: CONCEPT, CHALLENGES AND POSSIBILITIES}

\begin{abstract}
This article is a cut of the scientific initiation research (FAPESP) held in two municipal public schools, which aims to investigate the participation of students in the management of public school, cycle I of elementary school. However, the purpose of this article is to identify and reflect the school team's view on participation, emphasizing concept, challenges and possibilities. The research is part of the qualitative approach and used as instruments in the production of data: bibliographic research, testimonials and content analysis. Empirical evidence has shown that subjects believe that participation is more related to being present. The challenges are centered on curriculum content, the number of disciplines, the anxiety of getting children to school, and the excessive time they spend in school. Regarding the possibilities, we emphasize: work with student representatives, projects, voting and freedom for decision and choice, creation of rules and work with extracurricular activities and activities of civility.
\end{abstract}

Keywords: Participation. School Team. Democracy. Students. 


\section{INTRODUÇÃO}

A escola atualmente precisa assegurar a todos uma base científica sólida, e uma formação cidadã crítica, isto significa que é preciso fornecer subsídios para que o acesso ao conhecimento universal acumulado durante os anos aconteça realmente. A capacidade da escola de gerar um ambiente de formação crítica, respeito mútuo e participação geral e igualitária dos atores deste processo, é algo dependente da criação de um clima propício de aprendizagem e qualidade de ensino. Para este alcance, a gestão da escola precisa ser democrática e participativa, a qual segundo Libâneo, Oliveira e Toschi (2012, p.447)

[...] baseia-se na relação orgânica entre a direção e a participação dos membros da equipe. Acentua a importância da busca de objetivos comuns assumidos por todos. Defende uma forma coletiva de tomada de decisões. Entretanto, uma vez tomadas às decisões coletivamente, advoga que cada membro da equipe assuma sua parte no trabalho, admitindo a coordenação e a avaliação sistemática da operacionalização das deliberações.

Diante disso, defendemos a ideia de fortalecer a gestão democrática na escola pública municipal com o intuito de qualificar a participação de todos e, desse modo, contribuir para melhorar a qualidade do ensino.

Segundo Beisiegel $(1988$, p. 21)

Uma escola que corresponda aos interesses populares não será, nunca uma escola que se limite a ensinar leitura, escrita, cálculo e outras notações elementares. Esta escola deverá ser, também, uma escola que discuta, ao mesmo tempo, o próprio conhecimento que está sendo transmitido, explicite os conceitos, os conteúdos ideológicos que estão sendo transmitidos.

Apesar de a gestão democrática ser recomendada legalmente na Constituição Federal de 1988 e na Lei de Diretrizes e Bases no 9394/96, “[...] essa determinação legal, por si só, não garante uma escola de qualidade e democrática. Esse fato mostra a necessidade de serem empreendidos esforços para a construção de uma escola realmente democrática" (SOUSA; CORRÊA, 2002, p.57). Aqui se apresenta um dos grandes desafios da escola pública atual.

Verificamos que a legislação articula a gestão democrática com a participação, pois conforme Libâneo, Oliveira e Toschi, (2012, p.450-451)

A participação é o principal meio de assegurar a gestão democrática, possibilitando o envolvimento de todos os integrantes da escola no processo de tomada de decisões e no funcionamento da organização escolar. A participação proporciona melhor conhecimento dos objetivos e das metas da escola, de sua estrutura organizacional e de sua dinâmica, de suas relações com a comunidade, e propicia um clima de trabalho favorável a maior aproximação entre professores, alunos e pais.

Interessante afirmar que "a participação democrática não se dá espontaneamente, sendo antes um processo histórico de construção coletiva, coloca-se a necessidade de se preparar mecanismos institucionais que não apenas viabilizem, mas também incentivem práticas participativas dentro da escola pública". (PARO, 2001 apud FERRI, MACEDO, SANTOS, 2012, p. 290).

A formação integral do sujeito, bem como a formação para a cidadania exige vivências democráticas no espaço da escola de educação básica. Afinal, "os alunos aprendem democracia 
vivendo e construindo sua comunidade democrática de aprendizagem e de vida" (PEREZ GOMES, 2000 apud LIBÂNEO; OLIVEIRA; TOSCHI, 2012, p.521).

Nesse sentido, esta pesquisa visa investigar a participação dos alunos na gestão da escola pública do ciclo I do ensino fundamental. Contudo, o objetivo deste artigo é identificar e refletir a visão da equipe escolar sobre participação, enfatizando conceito, desafios e possibilidades.

\section{METODOLOGIA}

Nossa pesquisa é desenvolvida em duas escolas públicas municipais ciclo I do Ensino Fundamental, situada no interior do Estado de São Paulo. Desenvolvemos a pesquisa com uma abordagem qualitativa, que segundo Godoy (1995) permite que a imaginação e a criatividade levem os pesquisadores a pesquisar diferentes temas, e assim se revestir de caráter inovador. A pesquisa qualitativa permite que o pesquisador análise o ponto de vista de todos os participantes, levando em conta tudo aquilo que é dito e apresentado ao pesquisador, esse tipo de abordagem permite uma maior relação/intimidade do pesquisador com o objeto de pesquisa, pressupondo que isso poderá intervir positivamente no resultado de sua pesquisa.

Na produção de dados utilizamos: a pesquisa bibliográfica, as descrições dos depoimentos e a análise de conteúdo.

A pesquisa bibliográfica refere-se ao levantamento e seleção da bibliografia publicada sobre o tema de estudo, em diferentes materiais, com o objetivo de colocar o pesquisador em contato direto com todo o material já escrito sobre o tema (LAKATOS; MARCONI, 1987).

Quanto à escrita dos depoimentos solicitamos aos quatro sujeitos (Diretora, Vice, Professora e Aluno) que relatassem livremente sobre o que pensam, entendem, acreditam que seja "Participação dos alunos na gestão da escola pública" (tema do depoimento).

$\mathrm{Na}$ análise de conteúdo um aspecto importante que Franco $(2008$, p.16) aponta está relacionada a necessidade de que nela as descobertas precisam ter base teórica, pois "toda análise de conteúdo implica comparações contextuais. Os tipos de comparações podem ser multivariadas. Mas, devem, obrigatoriamente, ser direcionados a partir da sensibilidade e da competência teórica do pesquisador".

Nesse sentido, foram criadas diversas categorias a partir da escrita dos depoimentos, contudo selecionamos quatro delas, as quais apresentavam fortemente a visão dos sujeitos, a saber:

a) Conceito de Participação;

b) Importância da participação dos alunos;

c) Participação dos alunos: sugestões e possibilidades;

d) Desafios à participação dos alunos.

Está pesquisa foi aprovada pelo Comitê de Ética em Pesquisa (CEP) da FCT/UNESP com número 30366414.0000 .5402 .

\section{RESULTADOS}

Construímos uma síntese dos depoimentos, a partir das categorias destacadas acima, articulando-as com os autores, bem como trechos dos depoimentos dos sujeitos mencionados.

\section{DISCUSSÃO}

\section{CONCEITO DE PARTICIPAÇÃO}

Ferri, Macedo e Santos (2012) apontam que a palavra participação quer dizer "tomar parte ou ter parte", ou seja, participar não é simplesmente "estar ali" de corpo presente é fazer daquilo algo próprio, onde as discussões, tarefas e problemas devam ser incorporados de modo que cada sujeito responsabiliza-se firmemente com o que lhe cabe. 
De modo a ampliar a visão sobre o conceito de participação, a autora Gohn (2011) entende que podemos analisar o conceito de participação com base em três níveis básicos: conceptual, político e da prática social, onde o termo participação está rodeado de diversas interpretações, na qual na democrática a ação de participar é entendida como repartir as tarefas por meio da construção coletiva, divisão esta entendida como uma parceria entre os segmentos.

Pateman (1992) identificou em suas pesquisas três tipos de participação ao qual acreditamos que estas estão presentes nas escolas, sendo elas: "pseudoparticipação" está ligada quando os superiores somente requisitam algum conselho à comunidade e/ou sua equipe; "participação parcial" onde os envolvidos se interagem dos assuntos/atividades desenvolvidas, porém quem define de fato o que será desenvolvido é somente um grupo, geralmente os diretores (tipo de participação que mais ocorre nas escolas) e, "participação total" a forma mais desejada e correta, onde todos os segmentos envolvidos possuam conhecimento e influência sobre a decisão final.

Em consonância com a autora, citamos a escrita de um dos sujeitos que entende que "a participação dos alunos é essencial para os estudos e para a vida, por que quando alguém participa além de ser divertido também se aprende [...]" (Depoimento do Aluno). A vivência de representar um grupo é um excelente espaço de formação e de exercício de cidadania ao aluno, bem como aos outros segmentos.

Acreditamos que a abertura inicia-se, conforme o pensamento da professora de uma das escolas pesquisadas que entende que "[...] Ouvir e dar importância no pensamento do aluno é ponto principal para estimular a participação [...]". Nesse sentido, aspectos como: abertura à participação, estímulo e valorização são essenciais à escola que se deseja democrática e participativa.

\section{IMPORTÂNCIA DA PARTICIPAÇÃO DOS ALUNOS}

A participação dos alunos na gestão da escola ainda se faz precária em relação ao que desejamos, entretanto indo ao encontro de Sarmento e Marques (2006) acreditamos que é preciso partir do princípio de que a participação dos alunos existe sim, mesmo que insuficiente. Dessa forma, partimos para um segundo pensamento de que agora é preciso tornar esta participação pública visivelmente. $E$, para que isso ocorra devemos dar vez e voz a elas, para que possam assumir coletivamente uma posição, as quais juntas busquem a transformação dessa realidade social atual marcada por injustiças e desigualdades.

Diante disso, destacamos o pensamento da professora de uma das escolas a qual entende que "Ouvir e dar importância no pensamento do aluno é ponto principal para estimular a participação [...] É preciso abrir espaço para que o estudante possa ser ouvido, e compreendido, mas também para que assuma seus deveres" (Professora- escola A).

Em relação às capacidades/habilidades que são desenvolvidas a partir do envolvimento e da participação dos alunos, os sujeitos mencionaram o trabalho de aguçar a criticidade. Mediante os momentos de discussão os alunos podem ser colocados a analisar criticamente a realidade social ao qual algumas pessoas são postas, além de desenvolver a autonomia, visto que a escola como espaço de formação também forma seus alunos para que saibam agir sobre diversas situações desconfortáveis e, uma outra capacidade mencionada seria a do trabalho de formação da personalidade infantil, para que as milhares de crianças que passam pela escola tenham consciência de suas ações, saibam discernir o certo do errado e se comprometam com a transformação social.

Acreditamos que o aluno como sujeito tem seus direitos e deveres, e que, no exercício dessa participação é que ele desenvolve a criticidade, autonomia e personalidade social, colocando-se no lugar do outro [...] Dentre as possibilidades de participação, os alunos resolvem conflitos e 
propõe idéias por meio de sua própria voz (Diretora- escola A) (grifos nosso).

Nesse sentido, os sujeitos acreditam que ao trabalharem bem essas três capacidades, formaremos alunos capazes de resolver conflitos por meio do diálogo, bem como propor e expor suas ideias, crenças e sugestões respeitando as opiniões dos outros.

\section{PARTICIPAÇÃO DOS ALUNOS: SUGESTÕES E POSSIBILIDADES}

Vale ressaltar que se desejamos uma sociedade participativa, que luta pelos seus direitos e cumpra com seus deveres, bem como exerça suas funções de cidadania, precisamos primeiramente formar essa sociedade. Para essa formação, a escola é uma das instituições que pode se tornar espaço de formação integral e promover nos alunos valores sociais, principalmente a necessidade de lutar por uma sociedade e por um país mais justo.

De modo a apontar algumas sugestões/estratégias para que esta participação se concretize e/ou ocorra nas escolas públicas brasileiras, identificamos ações como:

- Construir coletivamente com os alunos em sala de aula as regras que auxiliam na boa convivência nos espaços escolares entre os alunos, professor, equipe gestora e demais funcionários. Escrever e fixar essas regras na sala de aula para que possam ser revisitadas e alteradas sempre que necessárias.

- Explicar aos alunos a origem dos recursos financeiros que mantem o funcionamento da escola, além de conscientizar sobre a conservação e manutenção de espaços públicos.

- Elaborar Projetos Políticos Pedagógicos subsidiados pela realidade atual dos alunos, por meio do próprio envolvimento dos alunos na elaboração deste documento, questionando-os sobre o que eles acreditam ser necessário manter e/ou alterar na escola para que a qualidade do ensino se concretize.

- Incentivar momentos para debates ao longo do ano letivo com objetivo de formação crítica dos alunos subsidiados por diversos textos: poesia, crônicas, propagandas, desenhos, obras de arte, etc... Debates que tragam conhecimentos e que provoquem reflexões e mudanças de concepções e atitudes.

- Incentivar e valorizar os espaços de participação na escola, como Conselho de Escola, Grêmios estudantis.

A participação do estudante na gestão escolar deve-se iniciar na sala de aula, com debates, discussões e espaço para que o aluno seja um agente ativo de sua aprendizagem, expondo suas ideias e questionamentos [...] Para se conseguir uma participação efetiva nas decisões escolares é necessário respeito e diálogo entre todas as partes envolvidas (Professoraescola A) (grifos nosso).

[...] representante de sala [...] participação em Projetos [...] decisão nos passeios escolares (votação por sala) [...] votação nos eventos (brincadeiras) [...] elaboração das regras da sala [...] presença nas reuniões de pais (bimestral com grupos de alunos representantes) [...] livre acesso a direção, vice e coordenação (Diretora- escola A) (grifos nosso).

\section{DESAFIOS À PARTICIPAÇÃO DOS ALUNOS}

A pesquisa de Tomás e Gama (2011) evidenciou a promoção da participação infantil apenas para cumprimento da lei, o que não é de todo ruim. Atitudes como essa, que apenas solicitam a presença dos alunos nos momentos de decisões, influenciam negativamente a participação das crianças, visto que os poucos alunos que ainda se interessam em participar se sentem desmotivados. 
Algumas exigências já instituídas pela própria escola que interferem na não participação infantil, como: os conteúdos curriculares, a quantidade de disciplinas, a ansiedade de se escolarizar as crianças desde pequenas, bem como e principalmente o tempo que passam sentados na escola fazendo atividades que consideram exaustivas, são práticas desmotivadoras para a participação dos alunos. (TOMÁs; GAMA, 2011).

Faz-se necessário a reflexão sobre a culpabilização da não participação dos alunos neles mesmos. Contudo, claro que temos alunos que simplesmente não se interessam pelos assuntos que são tratados pela escola, porém defendemos a ideia que essa não participação pode estar ligada a ausência de incentivo e/ou valorização.

Nossa hipótese em relação a pouca participação dos alunos consiste na ausência de definição da participação e da compreensão real do seu significado. O que de fato significa ser parte da escola e do processo educativo. Estar presente não significa participar, a participação envolve conhecimento, posição política, consciência crítica e luta pela transformação.

\section{CONCLUSÃO}

Os dados empíricos evidenciaram que os sujeitos pesquisados demonstram que a participação está mais relacionada com o estar presente, do que uma participação nas discussões, debates e decisões. Para os sujeitos pesquisados a participação proporciona aprendizagem, pois ao se envolver com as atividades da escola, em especial, ele pode ampliar seu conhecimento sobre a democracia, a importância do voto e da voz de cada um, bem como compreender questões pedagógicas e de cidadania.

Sarmento e Marques (2006) acreditam que para haver de fato uma participação ativa das crianças na escola e/ou socialmente é preciso que os adultos reconheçam nelas a capacidade de agirem e pensarem sobre si e sobre os próprios adultos. Portanto, cabe aos adultos, tendo em vista que esta pesquisa envolve a escola do ciclo I, ou seja alunos na faixa etária de 6 a 10 anos de idade, oportunizarem espaço, incentivo e valorização para a participação desses sujeitos.

O que se deseja realmente é que a participação dos alunos seja uma participação ativa, onde por meio dos espaços oportunizados, eles possam colaborar de alguma forma para a transformação da realidade social atual, exercendo atitudes de cidadania frente ao mundo ao qual estamos inseridos e, cada vez mais ter atitudes críticas no contexto escolar e social.

Enfim, participação significa "tomar parte", não é simplesmente "estar ali" de corpo presente. Participar significa: discutir, debater, dividir tarefas, enfrentar desafios no coletivo. Participação democrática não ocorre espontaneamente. É necessário antes um processo histórico de construção coletiva, que incentivem e viabilizem práticas participativas dentro da escola e na sociedade.

\section{REFERÊNCIAS}

BEISIEGEL, C. R. Política educacional e programas de alfabetização. Ideias. A educação básica no Brasil e na América Latina: repensando sua história a partir de 1930, n. 1, p. 16-22. 1988.

FERRI, L. M. C. G.; MACEDO, M. E. C. M.; SANTOS, C. M. Projeto educativo, planejamento participativo e gestão escolar. In: SANTOS FILHO, J. C. (Org.). Projeto educativo escolar. Petrópolis: Vozes, 2012. p.280-310.

FRANCO, M. L. P. Análise de Conteúdo. Brasília: Líber Livro, 2008. 80 p.

GODOY A. S. Pesquisa qualitativa: tipos fundamentais. Revista de Administração de Empresas. São Paulo, v. 35, n.3, p, 20-29 Mai./Jun. 1995. 
GOHN, M. G. Conselhos gestores e Participação sociopolítica. 4.ed. São Paulo: Cortez, 2011. p.1532.

LAKATOS, E. M.; MARCONI, M. A. Metodologia do Trabalho Científico. 2. ed. São Paulo: Atlas, 1987.

LIBÂNEO, J.C.; OLIVEIRA, J.F; TOSCHI, M.S. Educação Escolar: políticas, estrutura e organização. 10 ed. ver. ampl. São Paulo: Cortez, 2012, 543 p.

PATEMAN, C. Participação e Teoria Democrática. Rio de Janeiro: Paz e Terra, 1992.

SARMENTO, T. MARQUES, J. A participação das crianças nas práticas de relação das famílias com as escolas. Interacções. n.2, p. 59-86 (2006).

SOUSA, J. V.; CORRÊA, J. Projeto Pedagógico: a autonomia construída no cotidiano da escola. In: DAVIS, Claudia. (et al). Gestão da escola: desafios a enfrentar. Rio de Janeiro: DP\&A, 2002. p.4775.

TOMÁS, C.; GAMA, A. Cultura de (não) participação das crianças em contexto escolar. Faculdade de Letras do Porto: Educação, Territórios e (Des)Igualdades, jan. 2011. 